\title{
Análise dos repertórios comportamentais de crianças em função do gênero e da faixa etária
}

\author{
Analysis of behavioral repertoires of children by gender and age \\ http://dx.doi.org/10.5007/2178-4582.2017v51n2p405
}

\begin{abstract}
Jéssica Prazeres Ballesteros Moura, Mirella Rodrigues Nobre, Tatiany Alves de Melo e Sheyla Christine Santos Fernandes

Universidade Federal de Alagoas, Maceió/AL, Brasil
\end{abstract}

\begin{abstract}
Crianças passam por construções sociais desde o nascimento que interferem de forma global no desenvolvimento. É comum seu agrupamento em categorias pré-estabelecidas socialmente, sendo uma delas o sexo, o que pode reforçar preconceitos e estereótipos de gênero. A presente pesquisa objetivou analisar os repertórios de comportamento em função do gênero e da faixa etária. Participaram do estudo 40 crianças, de 5 a 10 anos (média=7,68; DP=1,53), submetidas a uma manipulação experimental e subsequente inquérito sobre favoritismo grupal. Os resultados demonstraram que meninos acima de 7 anos não apresentaram favoritismo endogrupal, e os demais apresentaram aumento dos níveis de favoritismo endogrupal na ausência da norma social aplicada. As meninas, independente da idade e da condição favoreceram o próprio grupo ou apresentaram distribuições igualitárias. A internalização das normas sociais e a capacidade de geri-las em função de um contexto é uma possível responsável pela manifestação do favoritismo endogrupal.
\end{abstract}

Palavras-chave: crianças; normas sociais; favoritismo grupal; gênero.
Children go through social constructions that interfere globally in their development from birth. It is common to reunite those constructions in preestablished social categories, as gender, which may reinforce bias and gender stereotypes. This study aimed to analyze the behavioral repertoires as function of gender and age group. The study included 40 children from 5 to 10 years (mean $=7.68, S D=1.53)$, subjected to experimental manipulation and subsequent investigation of group favoritism. The results showed that boys over 7 year did not presented ingroup favoritism, and other showed increased levels of ingroup favoritism in the absence of social norm applied. The girls, regardless of age and condition, favored the group itself or equal distributions. The internalization of social norms and the ability to manage them in terms of a context may be responsible for the manifestation of ingroup favoritism.

Keywords: children; social norms; group favoritism; gender.

\section{Introdução}

Temas relacionados à violência e comportamentos agressivos, designados pelo termo bullying, são recorrentes em notícias atuais em nosso país durante as fases da infância e adolescência. As mídias (livros, televisão, internet, música, tablets, telefone, jogos eletrônicos, dentre outras), sendo uma importante fonte de valores com as quais as crianças têm contato desde cedo, exercem influência em suas formações. Estas reproduzem os constantes episódios praticados motivados por preconceitos e intolerâncias presentes no cotidiano de muitas crianças, colocando, assim, as desigualdades em destaque (LISBOA; BRAGA; EBERT, 2009; NERY, 2012). Alguns estudos apontam 
que a mídia exerce, portanto, importante função pedagógica na educação infantil (MOREIRA, 2003).

Uma pesquisa do Ministério da Saúde realizada pelo Instituto Brasileiro de Geografia e Estatística (IBGE) - Pesquisa Nacional da Saúde do Escolar (PeNSE) - destacou que no período de 2009 a 2012 os casos de bullying nas escolas brasileiras, públicas e particulares, aumentaram de $5 \%$ para $7 \%$. É posto em destaque também que $20,8 \%$ dos estudantes afirmaram ter praticado bullying com colegas, tendo esta prática de discriminação seus maiores índices entre crianças do sexo masculino (MALTA et al., 2014).

As pessoas apresentam crenças e atitudes preconceituosas desde a infância, perdurando até a fase adulta, quando as expressões do preconceito tornamse mais camufladas. Até os cinco anos de idade, as crianças expressam a discriminação de maneira mais explícita e direta, no entanto, por volta dos sete anos de idade, pode-se observar uma diminuição nos níveis do preconceito, fazendo com que a criança passe a tolerar mais as diferenças (ABOUD, 1988).

França e Monteiro (2004) justificam que a diminuição na forma de expressão do preconceito se dá graças à introjeção das normas sociais vigentes em cada sociedade e cultura, fazendo com que, a partir de certa idade, o preconceito não seja mais explícito abertamente, adquirindo um caráter mais sutil e disfarçado.

As crianças passam por construções sociais desde seu nascimento, podendo influenciar em suas atitudes, gestos, valores e opiniões futuras de acordo com o seu sexo. Esta educação é mostrada de acordo com práticas sexistas, sendo as diferenças de gênero, na grande maioria dos casos, legitimadas naturalmente e de forma imperceptível nas relações interpessoais. A sociedade legitima estas diferenças e contribui para a formação de estereótipos que distanciam meninos e meninas em suas relações cotidianas, como em formação de grupos para brincadeiras, rodas de conversa e estudos (SANTOS; SOUZA, 2010).

A partir dos três anos a criança já é capaz de fazer distinções de gênero e é através da interação que estas diferenças são percebidas, possibilitando que diferentes padrões de comportamento sejam estabelecidos, e estes irão persistir durante sua vida adulta (CERQUEIRA-SANTOS; BOURNE, 2015; SOUZA; RODRIGUES, 2002). É a partir desta idade que a tendência à composição de grupos segregados sexualmente aparece e aumenta progressivamente durante os anos pré-escolares, atingindo seu ápice aos cinco anos (PAPALIA et al., 2006; SOUZA; RODRIGUES, 2002).

Segundo Nesdale (1999), as atitudes de uma criança em relação aos grupos externos ao seu (exogrupos) têm relação direta com o seu nível de 
desenvolvimento. As crianças muito novas mantém sua atenção sobre elas mesmas e suas preferências, e a partir dos cinco anos de idade tem início mais claramente o processo de categorização, isto é, as crianças passam a encaixar os indivíduos dentro de categorias. Estas são estabelecidas para a criança de acordo com as suas experiências, com o que foi aprendido anteriormente e pelo que lhe foi apresentado socialmente. É declaradamente exposto nessa fase o favoritismo ao próprio grupo (endogrupo) e, a partir disto, atitudes hostis podem ser expressas pelas crianças em direção aos exogrupos. Dos sete anos em diante é possível observar uma maior concentração das crianças nas características específicas de cada indivíduo, independentemente da categoria de pertença (NESDALE, 1999).

Os grupos de amizades começam a ser formados a partir da terceira infância, ou seja, por volta dos seis anos de idade. Estes se formam de maneira espontânea, entre crianças que estejam próximas fisicamente uma das outras (mesmo bairro, mesma escola etc.). Comumente são formados por indivíduos com idades próximas, de mesma origem racial ou étnica e com condições socioeconômicas semelhantes, e também por similaridades de gênero, e preferência pelas mesmas atividades. As similaridades de gênero e etnia são aspectos particularmente importantes para a exclusão de pares (ABOUD; MENDELSON, 1996; PAPALIA et al., 2013).

As amizades na infância são de extrema importância para o desenvolvimento de habilidades sociais, uma vez que promovem o senso de afiliação e o senso de identidade. Também são importantes para aquisição de habilidades de liderança, de comunicação, de cooperação, de regras e de papeis. $\mathrm{O}$ grupo de amizade possibilita ainda a maior expressão de emoções, o que promove um ambiente favorável para o desenvolvimento afetivo e emocional. Assim, o grupo de amigos ajuda a criança a aprender a se relacionar em sociedade, adaptando suas necessidades e desejos àquilo que for mais adequado para cada situação (PAPALIA et al., 2013; SENA; SOUZA, 2010). Para Carvalho e Pedrosa (2002) os grupos de crianças funcionam como microssociedades, tendo a criança como agente de criação, partilha e transmissão de cultura, é através dele que se dá o desenvolvimento.

Por outro lado, o grupo pode exercer influências negativas para as crianças, como por exemplo, ter a tendência a reforçar preconceitos através de atitudes desfavoráveis em relação a membros de grupos distintos, podendo gerar agressões de diferentes tipos. Entre as crianças em idade pré-escolar (6-7 anos) é comum observar a agressão explícita (agressão que visa ferir o alvo através de força ou ameaça física) e entre as crianças mais velhas, é comum observar a agressão relacional ou social (agressão que visa a um objetivo, como por exemplo, depreciar e provocar) (PAPALIA et al., 2013). 


\section{Comportamento de intolerância na infância}

Durante a idade escolar as expressões de intolerância aos grupos externos podem ser difundidas de forma preocupante, uma vez que, é neste período que as crianças adquirem conhecimento social, atitudes e comportamentos que podem perdurar na vida adulta e que, no caso do preconceito e da discriminação, chegam a ter um potencial para causar danos psicológicos e físicos de curto e de longo prazo para os jovens que são membros de grupos minoritários (DURKIN, 1995).

Sisto e Oliveira (2007) afirmam que uma atitude hostil ou um comportamento agressivo é desencadeado através da interação de variáveis pessoais e situacionais que podem aumentar ou diminuir o nível de ativação necessário para impulsionar tal comportamento. Leme (2004) afirma que muitos dos comportamentos agressivos revelam-se após os 10 anos de idade e tendem a se estender durante a vida adulta, além disso o autor cita que são as variáveis pessoais, como a personalidade, que irão formar o seu potencial de agressão, dando direção ao seu comportamento.

É possível verificar que o comportamento pode ser transferido de acordo com o contexto em que a criança está inserida, já que nem todos que reagem com agressividade em casa fazem o mesmo na escola, ou que demonstram atitudes agressivas na escola reagem da mesma forma em casa (SISTO; OLIVEIRA, 2007).

$\mathrm{Na}$ sociedade brasileira as formas de comportar-se não são homogêneas, mas categorizadas, na maioria das vezes, de maneira oposta (homens/mulheres; adultos/crianças; meninos/meninas). As crianças necessitam descobrir ou decidir quem são e onde se encaixam e, para isto, comparam pares e acabam se associando com indivíduos com quem têm maior identificação, sendo comum a divisão de grupos por sexo (SILVA et al., 2006). Neste sentido, a identidade de gênero, ou seja, a consciência de gênero e tudo que isso implica, é um aspecto de suma importância no desenvolvimento do autoconceito na infância (PAPALIA et al., 2013).

As diferenças entre os sexos podem ser explicadas através dos papeis e estereótipos de gênero. Os papeis de gênero são comportamentos, interesses, atitudes, habilidades e traços de personalidade considerados apropriados para homens e mulheres. Assim, na maioria das culturas as mulheres devem, por exemplo, dedicar a maior parte do seu tempo ao cuidado da casa e dos filhos, enquanto os homens devem ser os provedores e protetores do lar. Já os estereótipos de gênero são generalizações preconcebidas sobre como devem ser o comportamento masculino e feminino (PAPALIA et al., 2013). 
Nos grupos de amizade a criança é vista como agente de criação, partilha e transmissão de cultura, sendo através destes que se dá o desenvolvimento social, emocional e cognitivo (CARVALHO; PEDROSA, 2002; SOUZA et al., 2013), Por esta razão, as crianças tendem a repetir os papeis e estereótipos de gênero aprendidos socialmente em suas brincadeiras e em seus grupos. Portanto, as diferenças de gênero nas amizades têm um papel importante na socialização da criança, provendo o desenvolvimento de diferentes competências sociais entre meninos e meninas (SENA; SOUZA, 2010).

A diferenciação entre os sexos e a consciência do seu próprio se dá de maneira mais contundente para os meninos, pois estes são mais pressionados socialmente a desempenhar o papel masculino, uma vez que os estereótipos masculinos são menos flexíveis do que os femininos (APARECIDA, 2004).

Durante o processo de categorização, as crianças tendem a perceber e avaliar o comportamento de seu próprio grupo e dos demais, exagerando em diferenças com o exogrupo e nas similaridades do endogrupo (TAJFEL, 1982). É notório que as crianças de menor idade tendem a atribuir qualidades positivas a seu próprio sexo e qualidades negativas ao sexo oposto e é neste sentido que nascem as atitudes sexistas (PAPALIA et al., 2013).

\section{Algumas evidências empíricas sobre intolerância na infância}

O preconceito de gênero na infância pode ser percebido, em alguns casos, através das práticas do blullying, que chegam por comportamentos agressivos ou até mesmo por meio de uma linguagem ofensiva). O bullying pode ser entendido como ações agressivas, com repetições e intenção de praticá-lo, e que pode ocorrer sem uma motivação explícita, em ambientes onde há relações de desigualdades de poder, causando sofrimento e sentimento de angústia para a vítima destas atitudes discriminatórias, e que costuma causar sofrimentos físicos e psicológicos nas vítimas (CRISTOVAM et al., 2010; VIEIRA et al., 2016).

A partir desta definição, Cristovam et al. (2010) realizaram uma pesquisa com o objetivo de determinar a frequência de bullying, os locais de maior ocorrência, os motivos, a aceitação, os pedidos de ajuda e o conhecimento sobre a punição. Participaram deste estudo 534 estudantes de uma escola estadual do Paraná, com idades entre 10 a 16 anos, de ambos os sexos. Os autores verificaram que, entre todos os entrevistados, 421 se envolveram em ações agressivas, seja como vítima (112), autor (68) e ora autor, ora vítima (241). Entre os resultados encontrados, é válido pontuar que cerca de $80 \%$ das crianças que se identificaram como autores desses comportamentos eram do gênero masculino, e do grupo que se declarou como vítima, a maioria era 
do gênero feminino. Quanto aos motivos, foi colocado pelos participantes que se identificaram como autores que não havia a intenção de agredir, as atitudes iniciavam com brincadeiras. Os pedidos de ajuda eram voltados para os colegas e familiares, porém foi observado que quando o apoio era dado por seus pares os comportamentos agressivos eram reduzidos. É preciso que pais, professores e profissionais da saúde realizem um trabalho multiprofissional no intuito de criar estratégias de prevenção contra o bullying (CRISTOVAM et al., 2010).

Outro estudo sobre o tema foi realizado por Malta et al. (2012) com a finalidade de descrever a vitimização e a prática do bullying no âmbito escolar brasileiro, de acordo com os dados da segunda edição da Pesquisa Nacional da Saúde do Escolar (PeNSE 2012), realizada pelo IBGE a partir de uma parceria com o Ministério da Saúde. No PeNSE (2012), crianças do $9^{\circ}$ ano do ensino fundamental participaram do estudo, sendo solicitados a responder um questionário sobre o estudante e sua relação com o bullying (não ser bem tratado pelos colegas, sofrer bullying e praticá-lo). Dentre os principais resultados obtidos nesta pesquisa, é válido destacar que os estudantes do sexo masculino foram os que mais relataram a prática destas atitudes agressivas.

Estes resultados demonstram que os meninos estão mais envolvidos com a prática destes comportamentos, não afirmam, necessariamente, que eles sejam mais agressivos em relação às meninas, entretanto, é possível colocar que por questões culturais desenvolvidas e sustentadas pela sociedade, crianças do gênero masculino têm uma maior facilidade para agir com estes tipos de comportamento. Já para as meninas, não há esta possibilidade tão explícita, uma vez que entre elas são encontradas formas mais sutis de atitudes agressivas (SEGREDO, 2006).

Bandeira (2009) visou investigar a frequência dos possíveis motivos para a ação do bullying por sexo em 465 crianças de 9 a 18 anos de idade. A pesquisadora concluiu que houve uma diferença significativa entre os sexos, visto que mais de $44 \%$ dos meninos acreditam que estes comportamentos agressivos ocorrem por meio de brincadeiras, enquanto cerca de $27 \%$ das crianças entrevistadas do sexo feminino acreditam que estas atitudes ocorrem por outros motivos como preconceito e falta de respeito.

Nesta pesquisa foi verificada também a interação entre o sexo da criança ou adolescente e as práticas de bullying em relação à autoestima. Foi exposto nos resultados que no grupo de vítimas/agressores os meninos têm autoestima mais positiva que as meninas, indicando que o efeito nocivo de práticas discriminatórias possivelmente tem papel diferente em função do sexo. 
Diante do exposto, analisar as formas através das quais as crianças representam as relações de gênero parece bastante promissor no sentido de compreender alguns aspectos relacionados aos comportamentos discriminatórios ou intolerantes na infância. O presente estudo teve como finalidade analisar os repertórios de comportamento em função do gênero e da faixa etária em crianças de 5 a 10 anos de idade. Para tanto, foi realizada uma pesquisa experimental que como Variável Independente (VI) foi manipulada a ativação de uma norma social anti-preconceito de gênero e como Variáveis Dependentes (VD) foram averiguadas as condutas das crianças frente à distribuição de recompensas a meninos e meninas.

A partir da manipulação experimental, esperava-se que as crianças mais novas (5-7 anos de idade) favoreceriam o próprio grupo independentemente da ativação da norma e que as crianças mais velhas (8-10 anos de idade) favoreceriam o próprio grupo apenas na ausência da norma. Esperava-se também que os meninos evidenciassem um nível mais elevado de favoritismo endgrupal.

\section{Método}

Participaram desse estudo 40 crianças de escolas públicas e privadas da cidade de Maceió. Sendo 20 meninos e 20 meninas. Os participantes tinham idades entre 5 e 10 anos, e foram divididas em dois grupos ( 5 a 7 anos e 8 a 10 anos).

\section{Desenho:}

Foi utilizado um desenho fatorial de 2 (idade de 5 a 7 vs. de 8 a 10 anos) $\mathrm{X} 2$ (alvos menina vs. menino) X 2 (contexto de ativação da norma de gênero vs. Contexto de não ativação da norma de gênero: entrevistador presente vs. ausente).

\section{Procedimentos:}

Após autorização dos responsáveis pelas crianças, elas foram entrevistadas individualmente por uma entrevistadora, para os meninos e por um entrevistador, para as meninas. As entrevistas foram realizadas em um ambiente externo à sala de aula, disponibilizado por cada escola.

No primeiro momento, o(a) entrevistador(a) se apresentou à criança e em seguida as instruções foram passadas de acordo com o modelo proposto por França e Monteiro (2004) e adaptado para avaliar o preconceito de gênero: 
"Vou falar sobre um menino e uma menina que querem comprar bicicletas. Cada um deles quer sua própria bicicleta. Eu resolvi ajudá-los pedindo contribuição para eles às crianças das escolas. Para contribuir você tem só que colocar esse dinheiro (12 moedas de brinquedo de 1 Real $=0,35$ Cêntimos cada) nesses mealheiros. Veja! Outras crianças já contribuíram (a entrevistadora balança os dois mealheiros, produzindo ruído, para tornar credível a informação que acaba de dar). Você dá quanto quiser e do jeito que quiser. O dinheiro que você der, vai ser transformado em dinheiro de verdade e depois dado a eles."

Em frente à criança estavam dispostos 12 moedas de brinquedo e dois mealheiros com duas fotos, uma em cada mealheiro, sendo uma de um menino e outra de uma menina. Na primeira etapa do estudo o(a) entrevistador(a) permanecia acompanhando integralmente a criança enquanto esta distribuía os recursos. Na segunda etapa o(a) entrevistador(a) fornecia um pretexto qualquer à criança e se ausentava, deixando-a distribuir o recurso em sigilo. Desta forma, a variável "saliência da norma de gênero" foi operacionalizada, através da presença vs. ausência do(a) entrevistador(a): a norma estava saliente quando o(a) entrevistador(a) permanecia acompanhando a criança enquanto realizava a tarefa, e não estava saliente quando o(a) entrevistador(a) se ausentava da sala após ter dado as instruções. Posteriormente todas as respostas foram anotadas, bem como os dados da criança.

Para as análises utilizou-se o programa Statistical Package for Social Science (SPSS) versão 21. Foi realizado o teste estatístico Qui-Quadrado a fim de comparar as variáveis envolvidas. Adotou-se o grau de significância de $\mathrm{p}<0,05$ com margem de confiança de $95 \%$.

\section{Resultados}

Ao categorizar a amostra de participantes quanto ao gênero e idade (Grupo Etário 1 - 5 a 7 anos; Grupo Etário 2 - 8 a 10 anos), observou-se que a manipulação da norma de gênero apresentou as seguintes distribuições de recompensas aos alvos: na condição de saliência da norma, os meninos mais novos favoreceram o alvo masculino em duas ocasiões, o alvo feminino em 1 ocasião e realizaram distribuição igualitária em duas ocasiões. Os meninos mais velhos, considerando o mesmo contexto de resposta, favoreceram o alvo feminino em duas ocasiões, o alvo masculino em uma ocasião e realizaram duas distribuições igualitárias $\left(\mathrm{X}^{2}=0,680 ; \mathrm{gl}=2 ;\right.$ n.s. $)$.

Considerando a condição de ausência da norma, os meninos mais novos favoreceram o alvo masculino em três situações, realizaram duas distribuições 
igualitárias e não favoreceram o alvo feminino. Os meninos mais velhos, na mesma condição, favoreceram o alvo feminino em três situações, o masculino em duas e não realizaram nenhuma distribuição igualitária. Foi possível constatar que para o contexto de resposta com a ausência da norma social manipulada, foram encontradas diferenças estatisticamente significativas $\left(\mathrm{X}^{2}\right.$ $=7,133 ; \mathrm{gl}=2 ; \mathrm{p}=0,028$.) (Tabela 1$)$.

Tabela 1: Frequência de favorecimento aos alvos realizada pelas crianças do sexo masculino

\begin{tabular}{|c|c|c|c|c|c|c|}
\hline \multirow{2}{*}{\multicolumn{3}{|c|}{ Contexto de Resposta }} & \multicolumn{3}{|c|}{ Alvo Favorecido } & \multirow{3}{*}{$\begin{array}{c}\text { Total } \\
\\
\\
5\end{array}$} \\
\hline & & & \multirow{2}{*}{$\begin{array}{c}\text { Menina } \\
\\
1\end{array}$} & \multirow{2}{*}{$\begin{array}{c}\text { Menino } \\
\\
2\end{array}$} & $\begin{array}{l}\text { Distribuição } \\
\text { igualitária }\end{array}$ & \\
\hline \multirow{3}{*}{ Saliência da Norma } & & 1 & & & 2 & \\
\hline & Grupo Etário & 2 & & & & 5 \\
\hline & \multicolumn{2}{|l|}{ Total } & 3 & 3 & 4 & 10 \\
\hline \multirow{3}{*}{ Ausência da Norma } & \multirow[t]{2}{*}{ Grupo Etário } & 1 & $0^{*}$ & $3 *$ & & 5 \\
\hline & & 2 & $3 *$ & $2^{*}$ & $0^{*}$ & 5 \\
\hline & \multicolumn{2}{|l|}{ Total } & 3 & 5 & 2 & 10 \\
\hline \multirow{2}{*}{ Total } & Grupo Etário & 1 & & 5 & 4 & 10 \\
\hline & \multicolumn{2}{|l|}{ Total } & 6 & 8 & 6 & 20 \\
\hline
\end{tabular}

*Diferenças estatisticamente significativas

O grupo de participantes do sexo feminino de menor idade, na condição de ativação da norma social, favoreceu o alvo feminino em duas situações, o alvo masculino em uma situação e por duas vezes distribuiu igualmente as recompensas. As meninas mais velhas favoreceram o próprio grupo em uma ocasião, realizaram quatro distribuições igualitárias e não houve favorecimento do alvo masculino $\left(\mathrm{X}^{2}=2,406 ; \mathrm{gl}=2 ; \mathrm{n} . \mathrm{s}\right.$. $)$.

Com a ausência da norma social, as meninas mais novas favoreceram o próprio grupo em três situações, realizaram duas distribuições igualitárias e não favoreceram o alvo masculino. As meninas mais velhas por duas vezes favorecem os alvos masculinos e feminino e realizaram uma distribuição igualitária (Tabela 2) $\left(X^{2}=2,533 ; g l=2 ;\right.$ n.s. $)$. 
MOURA, J. P. B., NOBRE, M. R., DE MELO, T. A.; FERNANDES, S. C. S. Análise dos repertórios...

Tabela 2: Frequência de favorecimento aos alvos realizada pelas crianças do sexo feminino

\begin{tabular}{|c|c|c|c|c|c|c|}
\hline \multirow{2}{*}{\multicolumn{3}{|c|}{ Contexto de Resposta }} & \multicolumn{3}{|c|}{ Alvo Favorecido } & \multirow[t]{2}{*}{ Total } \\
\hline & & & Menina & Menino & Distribuição & \\
\hline \multirow{3}{*}{ Saliência da Norma } & & 1 & 2 & 1 & 2 & 5 \\
\hline & & 2 & 1 & 0 & 4 & 5 \\
\hline & \multicolumn{2}{|l|}{ Total } & 3 & 1 & 6 & 10 \\
\hline \multirow{3}{*}{ Ausência da norma } & & 1 & 3 & 0 & 2 & 5 \\
\hline & 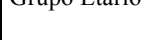 & 2 & 2 & 2 & 1 & 5 \\
\hline & \multicolumn{2}{|l|}{ Total } & 5 & 2 & 3 & 10 \\
\hline \multirow{3}{*}{ Total } & & 1 & 5 & 1 & 4 & 10 \\
\hline & Urupo Etario & 2 & 3 & 2 & 5 & 10 \\
\hline & \multicolumn{2}{|l|}{ Total } & 8 & 3 & 9 & 20 \\
\hline
\end{tabular}

As análises referentes ao papel do sexo dos participantes nos níveis de favoritismo endogrupal demonstraram que meninos e meninas não diferem quanto ao padrão de resposta por gênero. Na condição de saliência da norma, os meninos favoreceram o próprio grupo e o alvo feminino de maneira semelhante (por três vezes), e realizaram quatro distribuições igualitárias. As meninas favoreceram o próprio grupo por três vezes, o alvo masculino em uma situação e realizaram seis distribuições igualitárias. Não foram evidenciadas diferenças estatisticamente significativas $\left(\mathrm{X}^{2}=1,449\right.$; $\mathrm{gl}=2$; n.s. $)$.

$\mathrm{Na}$ condição de ausência da norma, os meninos favoreceram o alvo feminino em três ocasiões, o masculino em cinco e realizaram duas distribuições igualitárias. Neste mesmo contexto as meninas favoreceram o alvo feminino em cinco situações, o alvo masculino em duas e realizaram três distribuições igualitárias (Tabela 3$)\left(\mathrm{X}^{2}=2,035 ; \mathrm{gl}=2 ;\right.$ n.s. $)$. 
Tabela 3: Frequência de favorecimento aos alvos em função do sexo

\begin{tabular}{|c|c|c|c|c|c|c|}
\hline \multirow{2}{*}{\multicolumn{3}{|c|}{ Contexto de Resposta Norma }} & \multicolumn{3}{|c|}{ Alvo Favorecido } & \multirow{3}{*}{$\begin{array}{c}\text { Total } \\
\\
\\
10\end{array}$} \\
\hline & & & \multirow{3}{*}{$\begin{array}{c}\text { Menina } \\
\\
3 \\
3\end{array}$} & \multirow{2}{*}{$\begin{array}{c}\text { Menino } \\
3\end{array}$} & \multirow{2}{*}{$\begin{array}{c}\text { Distribuição } \\
\text { igualitária } \\
4\end{array}$} & \\
\hline \multirow{3}{*}{ Saliência da Norma } & \multirow{2}{*}{ Sexo Criança } & Masculino & & & & \\
\hline & & Feminino & & 1 & 6 & 10 \\
\hline & \multicolumn{2}{|l|}{ Total } & 6 & 4 & 10 & 20 \\
\hline \multirow[t]{2}{*}{ Ausência da norma } & Sexo Criança & $\begin{array}{l}\text { Masculino } \\
\text { Feminino }\end{array}$ & 3 & 5 & $\begin{array}{l}2 \\
3\end{array}$ & 10 \\
\hline & \multicolumn{2}{|l|}{ Total } & 8 & 7 & 5 & 20 \\
\hline \multirow[t]{2}{*}{ Total } & Sexo Criança & $\begin{array}{l}\text { Masculino } \\
\text { Feminino }\end{array}$ & 6 & 8 & 6 & $\begin{array}{l}20 \\
20\end{array}$ \\
\hline & \multicolumn{2}{|l|}{ Total } & 14 & 11 & 15 & 40 \\
\hline
\end{tabular}

\section{Discussão}

Com o objetivo de analisar a resposta comportamental relativa à manipulação de uma norma social de gênero frente ao favoritismo grupal de crianças em função do gênero e da faixa etária, a presente pesquisa administrou uma norma de gênero em dois formatos, presença e ausência da norma. Era esperado que as crianças mais novas exibiriam o favoritismo endogrupal independente da norma social; as mais velhas apenas na condição de ausência da norma e que os meninos apresentariam índices mais elevados de favoritismo endogrupal. Adaptando o modelo de França e Monteiro (2004) para o estudo das relações de gênero, foi considerado que a presença de um entrevistador de sexo oposto ao da criança investigada tornaria saliente a norma que foi denominada de norma de gênero. Inversamente, a ausência deste entrevistador implicaria em um cenário sigiloso e, portanto, propício a respostas de favorecimento ao próprio grupo.

No contexto de saliência da norma social os meninos mais novos e mais velhos não apresentaram diferenças significativas em suas respostas, indicando que a idade dos participantes não interfere na percepção de ativação da norma utilizada. Com a ausência da norma social, contrariamente ao que se esperava, os meninos mais novos preferiram favorecer o próprio grupo e realizar distribuições igualitárias em detrimento do favorecimento ao alvo feminino. Já os meninos mais velhos apresentaram padrão de resposta semelhante à condição de saliência da norma social. Pode-se observar que o 
sigilo empregado na condição de ausência da norma social ativou nos meninos mais novos a adição de comportamentos de favoritismo endogrupal, dado esperado apenas para as crianças mais velhas.

Foi evidenciado também que as participantes do sexo feminino, independente da idade e da condição, favorecem o próprio grupo ou apresentam distribuições igualitárias em detrimento do favorecimento aos meninos. A hipótese da interferência do gênero no favoritismo endogrupal não foi confirmada, uma vez que os meninos mais novos apresentaram diferenças significativas em suas respostas frente à ausência da norma, implicando na preferência pelo próprio grupo ou distribuições igualitárias em detrimento do favorecimento das meninas, padrão semelhante ao apresentado pelas meninas. Muito embora a literatura evidencie que os meninos apresentam uma tendência maior à expressão de comportamentos agressivo e discriminatórios (BANDEIRA, 2009; MALTA et al., 2012), no presente estudo o índice de rejeição frente o exogrupo não apresentou interação com o gênero dos participantes.

Segundo a abordagem cognitiva do desenvolvimento, as crianças apresentam índices elevados de favoritismo endogrupal aos seis anos de idade, podendo se estender até os oito anos, período em que haveria uma redução na expressão deste favoritismo. Com o avançar da idade, as crianças, por já terem internalizado as normas sociais, processam as informações de modo diferenciado e são capazes de disfarçar o favoritismo a depender do contexto em que se encontram (FRANÇA; MONTEIRO, 2004). No entanto, foi evidenciado que as crianças do sexo masculino acima de sete anos de idade, mesmo em suas respostas sigilosas, não apresentaram respostas de favorecimento endogrupal, enquanto que os meninos abaixo dos sete anos de idade, ao que parece atentos à ativação da norma social, com a ausência da mesma apresentaram acréscimo em seus níveis de favoritismo do próprio grupo. Alguns estudos apontam que as crianças têm apresentado certo amadurecimento cognitivo precoce, seja pela ampla exposição a influências midiáticas, seja pela demasiada exposição a estímulos diversos frequente nos dias atuais (NERY, 2012).

O conceito de autorregulação proposto pela teoria social cognitiva de Bandura (1991), refere a existência de um processo consciente e voluntário de governo, que torna possível a gerência dos próprios comportamentos, pensamentos e sentimentos, guiados por padrões gerais de conduta. A autorregulação permite que se antecipem cognitivamente cenários construídos por ações e seus efeitos, de forma a vislumbrar e escolher cursos de ação que são mais convenientes. Portanto, a autorregulação possui um relevante papel no exercício da agência humana, uma vez que possibilita a reflexão 
acerca de qual a maneira mais adequada de se agir em cada situação (AZZI; POLYDORO, 2009). Foi possível observar que as crianças mais velhas aprenderam a autorregular-se de acordo com que é socialmente desejado, uma vez que deram uma resposta adequada independente da condição empregada no estudo. No entanto, é importante destacar que as crianças mais novas também apresentaram respostas atentas à norma social, indicando um padrão de conduta bastante autorregulado.

O desenvolvimento e as atitudes do indivíduo na fase infantil estão diretamente relacionados quanto ao seu sentimento voltado para o exogrupo. Logo, é notório que a partir dos cinco anos as crianças tendem a valorizar mais o endogrupo, podendo reagir negativamente ao grupo que não pertence (NESDALE, 1999). É neste mesmo sentido que Souza e Rodrigues (2002) afirmam que a criança com três anos já é capaz de fazer distinções de gênero, tendendo a compor grupos segregados sexualmente, o que aumenta progressivamente durante os anos pré-escolares, e atinge seu ápice aos cinco anos. Neste sentido, é possível afirmar que crianças de menor idade tendam a atribuir qualidades positivas a seu próprio sexo e qualidades negativas ao sexo oposto (PAPALIA et al., 2013; SOUZA; RODRIGUES, 2002).

Os resultados aqui apresentados, de forma geral, evidenciam que um possível responsável direto do favoritismo endogrupal e a consequente intolerância exogrupal parece ser o processo de internalização das normas sociais e a capacidade de geri-las em função do contexto, conforme destacam França e Monteiro (2004) acerca da expressão do racismo e sua estreita vinculação com as normas sociais. Foi possível evidenciar também que esse processo de internalização das normas sociais parece estar presente em crianças abaixo dos oito anos de idade. Sugerimos a realização de pesquisas mais amplas e que considerem a manipulação de distintos contextos de resposta, pois trata-se de uma temática de grande relevância. A utilização de delineamentos experimentais entre participantes parece ser o caminho mais provável para a obtenção de respostas consistentes, contudo expõe a pesquisa a algumas limitações em relação à dificuldade de aplicação/alocação dos grupos e controle rigoroso das variáveis.

\section{Referências}

ABOUD, F. E. Children and prejudice. Oxford: Blackwell. 1988.

ABOUD, F.; MENDELSON, M. Determinants of friendship selection and quality: Developmental perspectives. In: W. BUKOWSKI; A. NEWCOMB; W. HARTUP (Eds.), The company they keep: Friendship in childhood and adolescence. Cambridge: University Press, p. 87-112, 1996. 
APARECIDA, S. O sexismo nas aulas de Educação Física: uma análise dos desenhos infantis e dos estereótipos de gênero nos jogos e brincadeiras (Tese de doutorado) -Universidade Gama Filho, Rio de Janeiro, 2004.

AZZI, R. G.; POLYDORO, S. A. J. Autorregulação da aprendizagem na perspectiva da teoria sociocognitiva: introduzindo modelos de investigação e intervenção. Psicologia educacional, São Paulo, n. 29, 2009.

BANDEIRA, C. M. Bullyng: auto-estima e diferenças de gênero. Tese (Mestrado em Psicologia) - Instituto de Psicologia, Universidade Federal do Rio Grande do Sul, Porto Alegre, 2009 .

BANDURA, A. Selfregulation of motivation throught anticipatory and selfreactive mechanisms. In: Dienstbier, R. A. (Ed.). Perspectives on motivation: Nebraska symposium on motivation. Lincoln, University of Nebraska Press, v. 38, p. 69-164, 1991.

CARVAlHO, A. M. A; PEDROSA, M. I. Cultura no grupo de brinquedo. Estudos de Psicologia, Natal, v. 7, n. 1, p. 181-188, 2002.

CERQUEIRA-SANTOS, E.; BOURNE, J. Papéis de gênero nas brincadeiras de faz-de-conta de crianças adotadas por casais do mesmo sexo. Contextos Clínicos, São Leopoldo, v. 8, n. $1,2015$.

CRISTOVAM, M. A. S. et al. Atos de bullying entre adolescentes em colégio público de Cascavel. Adolescência \& Saúde, Rio de Janeiro, v. 7, n. 4, p. 46-54, out./dez. 2010.

DURKIN, K. Developmental social psychology: From infancy to old age. Oxford: Blackwell, 1995.

FRANÇA, D. X.; MONTEIRO, M. B. A expressão das formas indirectas de racismo na infância. Análise Psicológica, Lisboa, v. 22, n. 4, p. 705-720, 2004.

LEME, M. I. S. Resolução de conflitos interpessoais: interações entre cognição e afetividade na cultura. Psicologia: Reflexão e Crítica, Porto Alegre, v. 17, n. 3, p. 367-380, 2004.

LISBOA, C.; BRAGA, L. L.; EBERT, G. O fenômeno bullying ou vitimização entre pares na atualidade: definições, formas de manifestação e possibilidades de intervenção. Contextos Clínicos, São Leopoldo, v. 2, n. 1, jun. 2009.

MALTA, D. C. et al. Bullying em escolares brasileiros: análise da Pesquisa Nacional de Saúde do Escolar (PeNSE 2012). BRAS EPIDEMIOL SUPPL PeNSE, p. 92-105, 2014.

MOREIRA, A S. Cultura Midiática e Educação Infantil. Educação \& Sociedade, Campinas, v. 24, n. 85, p. 1203-1235, 2003.

NERY, L. B.. Estereótipos de gênero: o efeito da exposição à mídia filme sobre brincadeiras de crianças. 2012. 158 f. (Dissertação de Mestrado) - Instituto de Psicologia, Universidade de Brasília, Brasília. 2012.

NESDALE, D. Social identity and ethnic prejudice in children. Psychology and Society, p. 92-110, 1999. 
PAPALIA, D. E.; OLDS, S. W.; FELDMAN, R. D. Desenvolvimento humano. Porto Alegre: ARTMED, 8 a ed., 2013.

SANTOS, P. J.; SOUZA, E.Q. Práticas sexistas na educação infantil: uma questão de gênero. Enciclopédia biosfera, Goiânia, v. 6, n.11, p. 01-08, 2010.

SEGREDO, N. C. Agresión entre pares (bullying) en un centro educativo de Montevideo: estudio de las frecuencias de los estudiantes de mayor riesgo. Revista Medica Del Uruguay. Montevideo, v. 22, p. 143-151, 2006.

SENA, S. S.; SOUZA, L. K. Amizade, infância e TDAH. Contextos Clínicos, São Leopoldo, v. 3, n. 1, jun. 2010.

SILVA, L. I. C.; PONTES, F. A. R.; SILVA, S. B.; MAGALHÃES, C. M. C.; BICHARA, I. D. Diferenças de gêneros nos grupos de brincadeira na rua: a hipótese de aproximação unilateral. Psicologia: Reflexão e Crítica, Porto Alegre, v. 19, n. 1, pp. 114-121, 2006.

SISTO, F. F.; OLIVEIRA, A. F. Traços de personalidade e agressividade: um estudo de evidência de validade. PSIC - Revista de Psicologia Vetor Editora, São Paulo, v. 8, n. 1, p. 89-99, jan./jun 2007.

SOUZA, F.; RODRIGUES, M. M. P. A segregação sexual na interação de crianças de 08 e 09 anos. Psicologia: Reflexão e Crítica, Porto Alegre, v. 15, n. 3, p. 489-496, 2002.

SOUZA, L. K. de; SILVEIRA, D. C.; ROCHA, M. A. Lazer e amizade na infância: implicações para saúde, educação e desenvolvimento infantil. Psicologia e educação, São Paulo, n. 36, p. 83-92, jun. 2013.

TAJFEL, H. Grupos humanos e categorias sociais. Lisboa: Livros Horizontes, 1982.

VIEIRA, I. S. et al. Atitudes de alunos expectadores de práticas de bullying na escola/Attitudes of bullying practices bystanders students at school. Ciência, Cuidado e Saúde, v. 15, n. 1, p. 163-170, 2016.

Jéssica Prazeres Ballesteros Moura é discente em Psicologia na Universidade Federal de Alagoas, Maceió, Brasil.

End.: Rua Dr. Noel Nutels, n. 104, Edf. Cartago, apto. 902. Bairro: Ponta Verde, CEP: 57035-450.

E-mail: je.ballesteros@gmail.com

Mirella Rodrigues Nobre é discente em Psicologia na Universidade Federal de Alagoas, Maceió, Brasil. E-mail: mirellarodriguesnobre@,hotmail.com

Tatiany Alves de Melo é discente em Psicologia na Universidade Federal de Alagoas, Maceió, Brasil. E-mail: tatianyamelo@gmail.com 
MOURA, J. P. B., NOBRE, M. R., DE MELO, T. A.; FERNANDES, S. C. S. Análise dos repertórios...

Sheyla Christine Santos Fernandes é doutora em Psicologia, docente na Universidade Federal de Alagoas, Maceió, Brasil. E-mail: sheylacsfernandes@msn.com.br 